\begin{tabular}{ccc}
\hline International Journal of Engineering \& Technology, $9(3)(2020) 718-723$ \\
SPC & Website: www.sciencepubco.com/index.php/IJET \\
Research paper & Intional Journal of Engineering \& Technology \\
\hline
\end{tabular}

\title{
Implementation of a developed water tunnels cleaning model with an automatic sensing and operation mechanism
}

\author{
Rasha Yasen Abd ${ }^{1}$, Ali Sachit Kaittan ${ }^{1}$, Raghad Ali Mejeed ${ }^{1}$ \\ ${ }^{1}$ Department of Power and Electrical Machine Engineering, University of Diyala, Diyala, Iraq \\ *Corresponding author E-mail: aliialzobaiidy@gmail.com
}

\begin{abstract}
Iraq contains two main rivers with several sub streams and tributaries. One of the most important problems in these streams and tributaries is the amount of waste on the water surface. This waste can lead to many issues such as diseases infection and affects the fisheries. River cleaning machine is one of the most important solutions for this problem. In this paper, a developed cleaning machine was designed based on Arduino and remote sensing mechanism to reduce the operation time and cost. The proposed cleaning machine model was tested and validated and can be used efficiently in many places under different conditions.
\end{abstract}

Keywords: Cleaning Machine; Arduino; Wiper Motor; Ultrasonic; Relay.

\section{Introduction}

Water is one of the basic requirements for humans and all other beings. Two-thirds of the Earth is water, but not all of them are suitable for human use because of the amount of waste in it and these wastes can cause dangerous diseases. Small rivers and streams are considered one of the most places where waste is collected and are a source of epidemic diseases [1]. The accumulation of these wastes the waters of these rivers can turn into dangerous black water. People who clean these rivers are exposed to contact with pollutants that negatively affect their health. And with the persistence of climate fluctuation and droughts in the summer, Small rivers and streams must be preserved and all waste scattered on their surface should be removed [2]. A design was suggested for a river cleaning machine. This enables the workers to clean the small rivers (tunnels) by operating the machine with a simple remote control and alarm sensors. The machine operator doesn't need much skill and it is looks very simple and economical [3].

\section{Materials and methods}

\subsection{Methodology}

The project is a stationary mechanical system, with electrical control that can be used in tunnels. The chain and gear wheel of conveyor movement are used which supplied fork plates to collect waste in rivers. The process of collecting the floating wastes will be happen when the chain along the plates starts to rotate and collecting the wastes in the bin that is placed beside of the system [4].

The project is placed in an opposite direction of the water flow floating wastes like plastic cans, bottles, covers etc., are lifted by lifters which are connected to the chain. When the first motor run, the two chains starts to circulate. First chain to lift the waste by lifter teeth upwards at angle of $(0-45)$ installed on oblique network and second chain installed on horizontally network moves the wastes by lifter teeth horizontally beside the river and stored in a collector bin[5].

The second motor move oblique network vertically depends on the depth of the river and the water level. The system consist Arduino Uno, two DC motor (wiper motor), Ultrasonic sensor, relay, chain, sprocket, bearing, 12V battery, Network, The RI transmitter transmits the signal as the switches are operated by human.

\subsection{Working}

When the machine is started by the operator, RI model transmitter transmits signal to Arduino Uno. The signal is transmitted from Arduino to relay to operate the motor, thus moving sprocket, chain and lifter teeth and collect wastes in a collector bin. To enhance the work, an ultrasound sensor was installed and connected to the Arduino to sense waste and auto play operation [6].

\subsection{Hardwar description}




\subsubsection{Arduino uno}

Electronic boards consisting of open source electronic circuit with a programmable controller that is designed to use interactive electronics and build different sensors such as temperature, wind, and ultrasound as shown in Figure 1. Uno Arduino can be downloaded in various programs from a computer and depends on the open programming language [7].

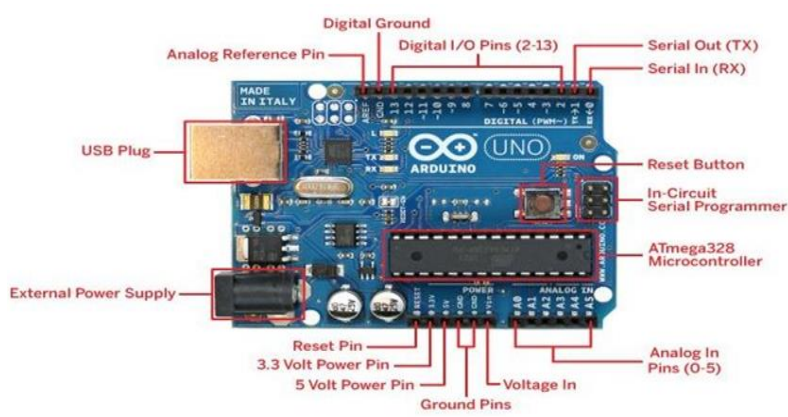

Fig. 1: Arduino Uno.

\subsubsection{Wiper motor}

Mechanism for converting rotational motion to linear motion using a DC wiper motor as shown in Figure 2. In this machine two wiper (12 D.C volts) motor had been used. The performance of wiper motor shown in Table1[8].

Table 1: Performance of Wiper Motor

\begin{tabular}{lll}
\hline \multirow{2}{*}{ Item } & Specifications & Limits \\
\hline \multirow{2}{*}{ No-load speed } & Motor function & $45 \pm 5 \mathrm{rpm}$ \\
& high speed & $30 \pm 5 \mathrm{rpm}$ \\
No-load current & low speed & $2.5 \mathrm{~A} \mathrm{Max}$ \\
& high speed & $1.5 \mathrm{~A} \mathrm{Max}$ \\
Brake & low speed & $71 \mathrm{~N} . \mathrm{m} \mathrm{Min}$ \\
Voltage & stall torque & $36 \mathrm{~A} \mathrm{Max}$ \\
Temperature rise & Current & DC $12 \mathrm{~V}$ \\
Weight & & $-40^{\circ} \mathrm{c}+65^{\circ} \mathrm{c}$ \\
\hline
\end{tabular}

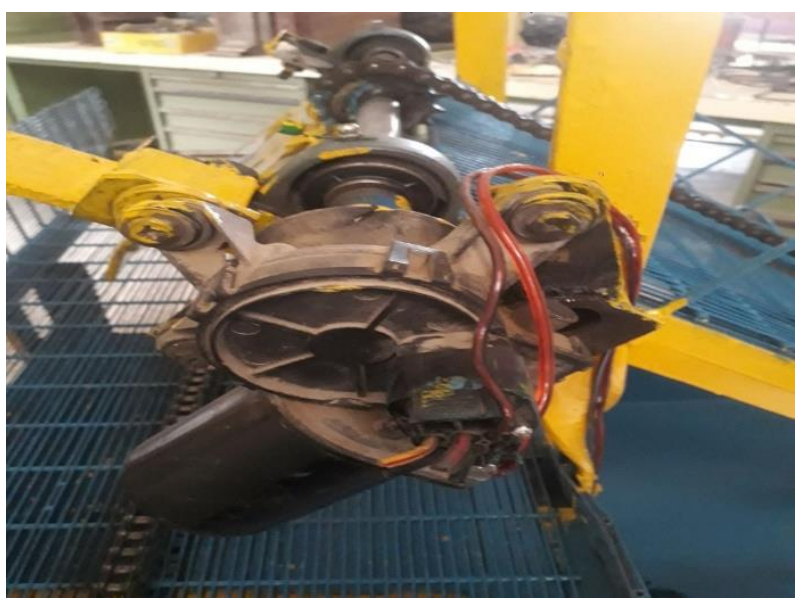

Fig. 2: D.C Wiper Motor.

\subsubsection{Ultrasonic}

The HC-SR04 ultrasonic sensor employments sonar to decide separate to a protest. It offers amazing non-contact extend location with tall precision and steady readings in an easy-to-use bundle. It comes total with ultrasonic transmitter and recipient modules. Automatically sends eight $40 \mathrm{kHz}$ and detect pulse signal back [9]. The ultrasonic is shown in Figure 3 and its specifications are as following:

Max static current: $2 \mathrm{~mA}$

Output of electrical level: $5 \mathrm{~V}$ High

Distance detection: $2 \mathrm{~cm}-450 \mathrm{~cm}$.

High precision: $2 \mathrm{~mm}$ 


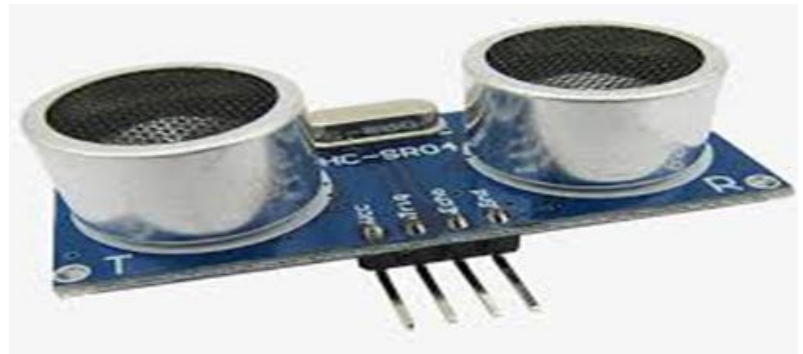

Fig. 3: Ultrasonic.

\subsubsection{Infrared remote control}

The overwhelming remote-control innovation in automation applications is infrared (IR). Infrared light is additionally known as plain-old "warm." The fundamental preface at work in an IR inaccessible control is the utilize of light to carry signals between a farther control and the gadget it's coordinating. Infrared light is within the undetectable parcel of the electromagnetic spectrum. An IR farther control (the transmitter) sends out beats of infrared light that speak to particular twofold codes. These parallel codes correspond to commands, as Control On/Off [10] .

\subsubsection{Relay}

Relay is an electrically worked switch. Numerous transfers utilize an electromagnet to mechanically work a switch, but other working standards are too utilized, such as solid-state transfers. Transfers are utilized where it is essential to control a circuit by an isolated lowpower flag, or where a few circuits must be controlled by one flag [11].

\subsubsection{Chain}

A chain which is shown in Figure 4, may be a serial get together of related pieces, called joins, routinely made of metal, with an by and expansive character comparative to that of a rope in that it is versatile and twisted in compression but coordinate, unbendable, and loadbearing in weight [12].

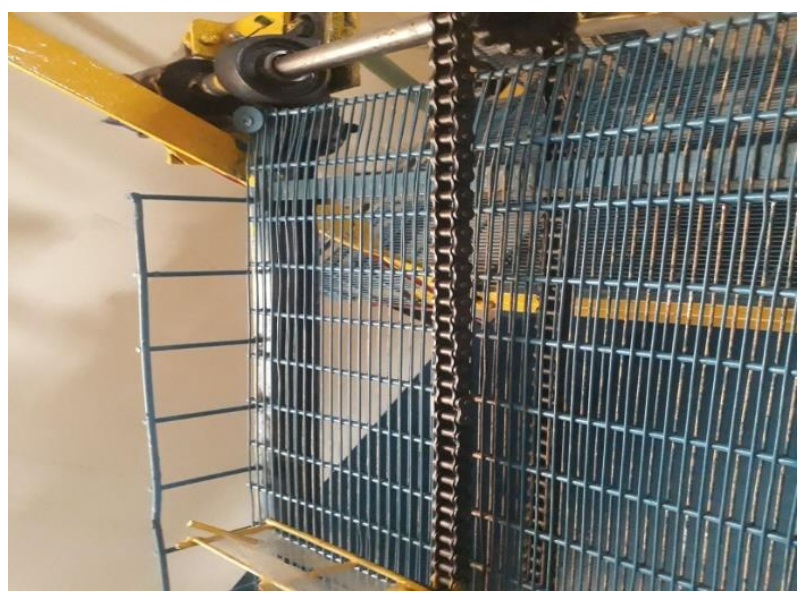

Fig. 4: Chain.

\subsubsection{Gear}

A prepare or cogwheel may well be a turning machine parcel having cut teeth, or inside the case of a cogwheel, inserted teeth (called $\operatorname{cogs}$ ), which work with another toothed parcel to transmit torque. Equipped gadgets can alter the speed, torque, and course of a control source. Gears almost continuously deliver a alter in torque, making a mechanical advantage, through their equip proportion, and hence may be considered a basic machine [13]. Figure 5 shows the type of gear which is practically used in this machine.

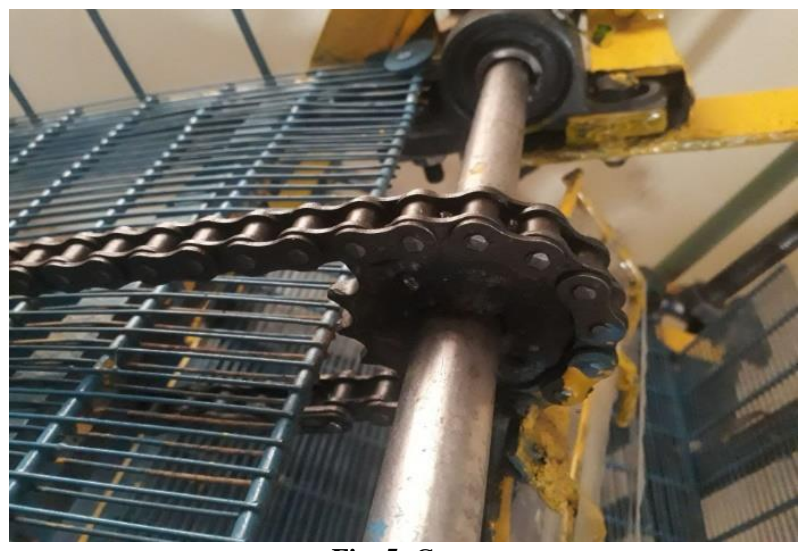

Fig. 5: Gear. 


\subsubsection{Bearing}

Bearing as shown in Figure 6, may be defined as a machine component which underpins another moving machine component. It grants a relative movement between the contact surfaces of the individuals, whereas carrying the stack [14].

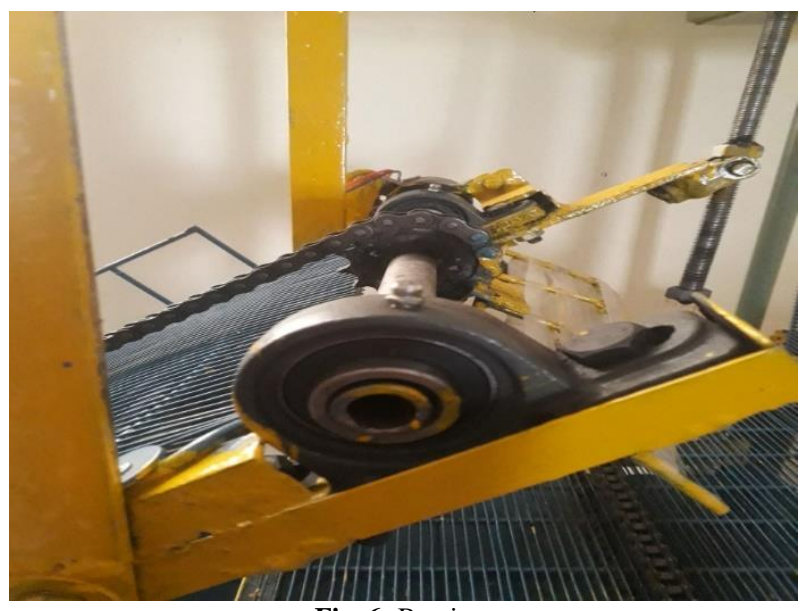

Fig. 6: Bearing.

\subsubsection{Shaft}

Shaft is the mechanical component for transmitting torque and revolution. Shaft estimate incredibly influences the torque in these machines it's shown in Figure 7 [15].

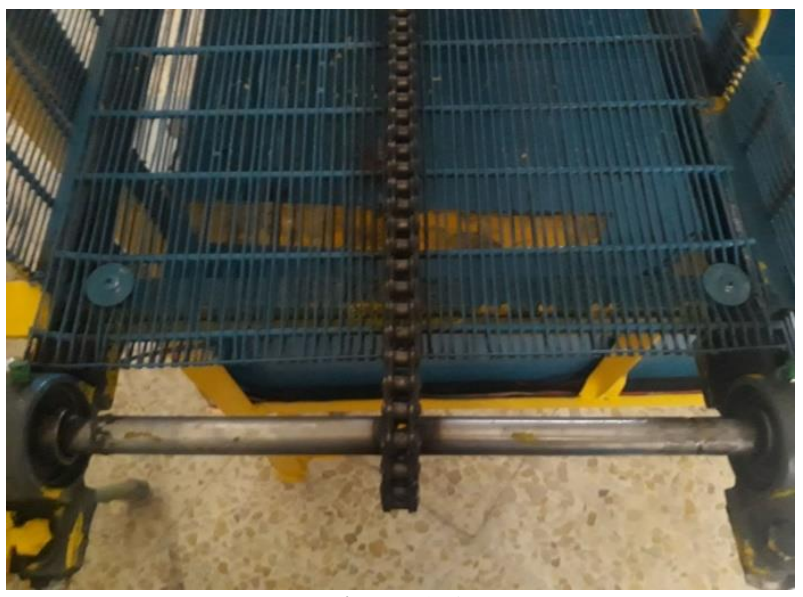

Fig. 7: Shaft.

\subsubsection{Base frame}

The base frame has been designed with a suitable dimensions as following:

Length $=150 \mathrm{~cm}$.

Width $=50 \mathrm{~cm}$.

Height $=60 \mathrm{~cm}$.

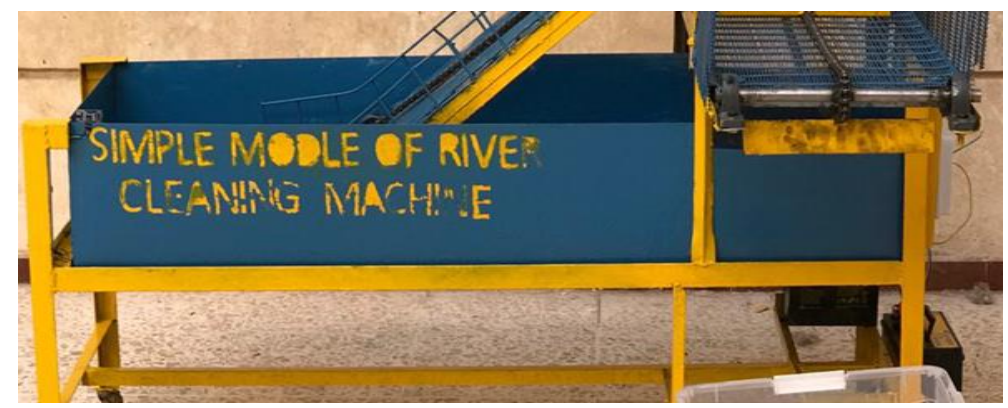

Fig. 8: Base Frame.

\section{Results and discussions}

After connected the mechanical and electrical parts of the machine, a test for its working has been done and approved practically. The results has approved that this machine is useful for cleaning the tunnels and streams proffecinally in our town. 


\subsection{Mechanical set up}

Final fabrication of the machine includes mechanical components and base farm for laboratory testing as shown in Figure 9. Once the design meets the requirements, the real time setup is fabricated.

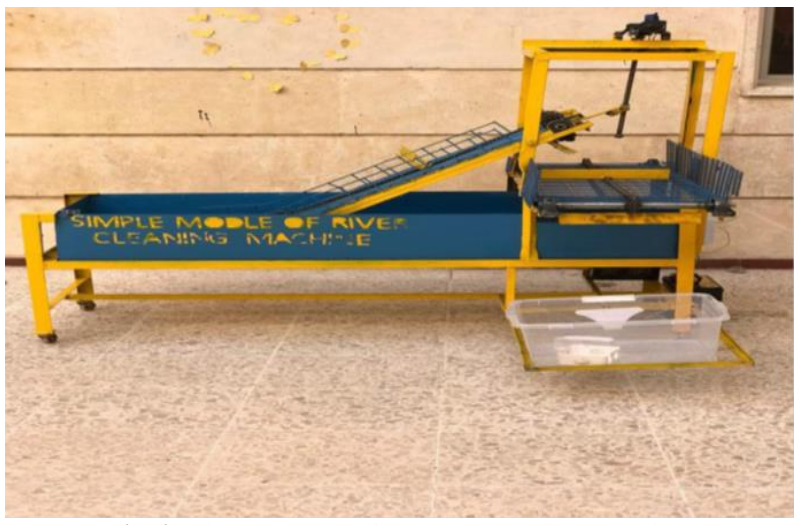

Fig. 9: Simple Model of Tunnels Cleaning Machine.

\subsection{Electrical set up}

Chief source of power for the complete electrical circuit design is battery. Motor, relays and switches are using for operative working of the project. IR transmitter and receiver are used for remote control process. The Arduino regulate the work of the ultrasound, motor. Thus, the electrical set up is shown in the Figure 10.

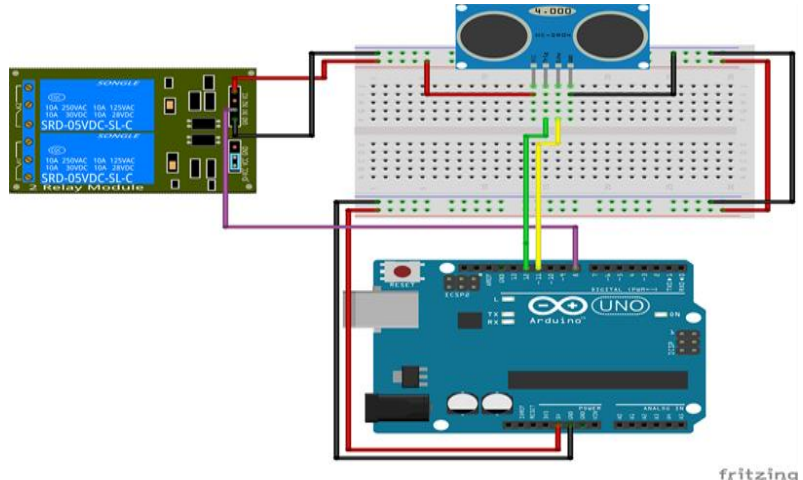

Fig. 10: Circuit of Ardouino.

\subsection{Cleaning machine application}

This machine is used in almost small rivers and streams (tunnels). It is an effective and low-cost method to solve a large part of the waste problems spread in tunnels, thus reducing diseases and upgrading dignity of work. The machine requires less power simple requirement with high efficiency. Large amount of waste is collected and sent for recycling.

\section{Conclusion}

Automation has become a requirement for modern services. The automatic river cleaning device helps reduce floating waste automatically and maintains the aquatic organisms in the rivers and reduces the spread of diseases. Dependency of the machine on a modern programming system that will lead to a reduction in time, submitted effort, cost, and lower energy consumption. the machine can be used in many places.

\section{Acknowledgement}

This machine had been outlined and actualized within the labs of electrical power and machines department of Engineering, College in Diyala University, so we are exceptionally grateful to all whom offer assistance us in execution this machine

\section{References}

[1] Saifali Sayyad, Adarsh Dorlikar, Sneha Ratnaparkhi, Nikhil Tonge, Tanvi Bhagat, Prof. Mahesh N. Buradkar,” Design and Fabrication of River Cleaning Machine", International Research Journal of Engineering and Technology (IRJET) Volume: 06 Issue: 05- May 2019.

[2] M. Mohamed Idhris, M.Elamparthi,C. Manoj Kumar, Dr.N.Nithyavathy, Mr. K. Suganeswaran, Mr. S. Arunkumar, "Design and fabrication of remote controlled sewage cleaning Machine", IJETT - Volume-45 Number2 -March 2017. https://doi.org/10.14445/22315381/IJETT-V45P214.

[3] Mr.Abhijeet.M. Ballade, Mr. Vishal.S. Garde, Mr.Akash.S. Lahane and Mr.Pranav.V.Boob, "Design \& fabrication of river cleaning system", IJMTER Volume 04, Issue 2, [February-2017] ISSN (Online):2349-974. 
[4] Mr. P. M. Sirsat, Dr. I. A. Khan, Mr. P. V. Jadhav, Mr. P. T. Date, "Design and fabrication of River Waste Cleaning Machine", IJCMES 2017 Special Issue-1 ISSN: 2455-5304. https://doi.org/10.24001/ijcmes.icsesd2017.27.

[5] Die Wasserkräfte, A. Ludin, Springer 1913, preface from Geh. Oberbaurat Dr.-Ing. Hermann Keller.

[6] Mattner, U. Wasser, Wehre und Turbinen, Beton-Verlag 1990, ISBN 3-7640- 0279-4

[7] Ludin, A., Die Wasserkräfte, I. + II. Band, Springer, 1913, Manuldruck 1922.

[8] Int. Seminar Wasserkraftanlagen, TU Wien 2006, ISBN 3-9501937-2-3, Conference Proceedings, p 189.

[9] Ehsani, M., Gao, Y., Gay, S. E. \& Emadi, A., (2005). Modern Electric, Electric, and Fuel Cell Vehicles - Fundamentals, Theory, and Design, first edn, CRC Press LLC. https://doi.org/10.1201/9781420037739.

[10] Abdullah, Ali Najim, and Mohammed Hassan Ali. "Direct torque control of IM using PID controller." International Journal of Electrical \& Computer Engineering (2088-8708) 10 (2020). https://doi.org/10.11591/ijece.v10i1.pp617-625.

[11] Ali Sachit Kaittan, "analysis and evaluation of power quality issues in computer-based generation system using custom power devices", in international journal of civil engineering and technology (IJCIET), vol 10, Issue 4 April 2019, pp. 1870-1879.

[12] Kaittan, Ali Sachit. "Comparison study between solid and litz wires of induction cooker." 2018 1st International Scientific Conference of Engineering Sciences-3rd Scientific Conference of Engineering Science (ISCES). IEEE, 2018. https://doi.org/10.1109/ISCES.2018.8340533.

[13] Pankaj Singh Sirohi, Rahul Dev, Shubham Gautam, Vinay Kumar Singh, Saroj Kumar,"Review on Advance River Cleaner", IJIR Vol-3, Issue-4, 2017 ISSN: 2454- 1362.

[14] Ndubuisi c. Daniels, "Drainage System Cleaner A Solution to Environmental Hazards", IRJES) ISSN (Online) 2319-183X, Volume3, Issue 3(March 2014).

[15] Osiany Nurlansa, Dewi Anisa Istiqomah, and Mahendra Astu Sanggha Pawitra, "AGATOR (Automatic Garbage Collector) as Automatic Garbage Collector Robot Model" International Journal of Future Computer and Communication,Vol. 3, No. 5, October 2014. https://doi.org/10.7763/IJFCC.2014.V3.329.

[16] Abood, Hatim G., Ghassan Abdullah Salman, and Ali Sachit Kaittan. "A Regularized Approach for Solving Ill-Conditioned State Estimation of Distribution Systems." Elektrotehniski Vestnik 86.3 (2019): 137-143.

[17] Dr.mohammed Saadi ,Dr Raghad Ali and Rasha yasen abd "Enhancement Mathematical Model of IM Drive using rotation Coordinate for Better Output performance", International Journal of Power Electronics and Drive System.

[18] AS Kaittan, SM Hameed, NK Ali, MH Ali, 'Smart management system for monitoring and control of infant baby bed' , International Journal of Electrical \& Computer Engineering, Vol 10, issue 5, October 2020, p. 5025. https://doi.org/10.11591/ijece.v10i5.pp5025-5031. 